\title{
End Tidal Carbon dioxide Monitoring-Its Reliability in Neonates
}

\author{
Sushma Nangia, Arvind Saili and A.K. Dutta \\ Department of Neonatal Medicine, Kalawati Saran Children's Hospital, \\ Lady Hardinge Medical College, New Delhi
}

\begin{abstract}
End tidal Carbon dioxide monitoring was undertaken prospectively in all Ventilated neonates in our NICU admitted from March 1995 to August 1995 irrespective of the birth weight, gestational age and indication of ventilation. The aim was to determine the correlation between $\mathrm{ETCO}_{2}$ and $\mathrm{PaCO}_{2}$ in various clinical situations. The arterial blood gases were obtained in all ventilated babies with simultaneous and continuous $\mathrm{ETCO}_{2}$ monitoring and were analysed by AVL $995 \mathrm{Hb}$ blood gas analyser. $\mathrm{ETCO}_{2}$ was analysed by side stream technique by Datex Cardiocap II monitor. A total of 152 samples from in-dwelling radial artery catheters were analysed from babies with birth weight from $900 \mathrm{~g}$ to $3400 \mathrm{~g}$, gestation age from 28 to 42 wks and were ventilated for various indications like Severe Birth Asphyxia (SBA), Meconium Aspiration Syndrome (MAS), Recurrent Apnoea and Hyaline Membrane Disease (HMD). Statistical analysis was done in 10 groups to see if the $\mathrm{ETCO}_{2}$ correlated with its corresponding $\mathrm{PaCO}_{2}$ value. The study groups comprised three groups based on birth weight being $<1.5-2.5 \mathrm{~kg}$ and $>2.5 \mathrm{~kg}$ three groups as per the gestational age being $28-31^{+6}$ wks, $32-36^{+6}$ wks and $37-41^{+6}$ wks and four groups as per the need for ventilation being Severe Birth Asphyxia, Meconium Aspiration Syndrome, Apnoea of Prematurity and Hyaline Membrane Disease. Results of the correlation analysis revealed that the correlation coefficient in the study group ranged from 0.55 to 0.96 and was statistically significant in babies $>2.5 \mathrm{~kg}$ and $1.5-2.5 \mathrm{~kg}$, in term and preterms $32-36 \mathrm{wks}$, and in babies with MAS, SBA and Recurrent Apnoea. The correlation coefficient was lowest in babies with HMD, being 0.55 . The study showed that $\mathrm{ETCO}_{2}$ correlates closely with $\mathrm{PaCO}_{2}$ in most clinical situations in neonates and we recommend its use in all level III NICUs in ventilated babies.
\end{abstract}

Key words: End tidal carbon dioxide; Non invasive monitoring; Neonatal ventilation.

Mechanical ventilation is an invasive life support undertaken to correct abnormalities in oxygenation $\left(\mathrm{PaO}_{2}\right)$, alveolar ventilation $\left(\mathrm{PaCO}_{2}\right)$ or respiratory effort (Poor, nil or difficult) with multiple effects on the cardiopulmonary system. ${ }^{1}$ To assess or ensure adequate gaș exchange, blood gases

Reprint requests: Dr. Sushma Nangia, B-1/1702, Vasant Kunj, New Delhi-110 070. need to be monitored. Arterial blood gases are the gold standard for assessing the adequacy of oxygen delivery, ventilation and $\mathrm{pH}$ and all non-invasive monitoring methods should be correlated with ABGs. ${ }^{1,2}$

Blood samples for arterial blood gas estimation are usually obtained from indwelling arterial catheters and less frequently by painful and technically 
difficult percutaneous arterial punctures. Indwelling catheters pose a serious risk of infection including fungal infections whereas percutaneous punctures can compromise blood flow to the extremity if the vessel goes into spasm and also the arterial punctures are highly stressful and painful and cause variable drops in $\mathrm{PO}_{2}$ especially in acutely ill neonates with little pulmonary reserve..$^{13,14}$

One of the problems with blood samples is that every sample is only a snapshot view of the sampling moment and in order to ensure that this snapshot view is representative of the patient's true condition, continuous monitoring before, during and after sampling is necessary. Continuous non-invasive monitoring reduces the number of blood samples needed and increases the value of the required samples. ${ }^{14}$ Iatrogenic anaemia is another big hazard leading to frequent blood transfusions which in the third world definitely pose serious risk" of blood transmissible infections like Hepatitis B, AIDS, CMV etc.

Arterial blood gas analysis is expensive as the cost of analysis of one sample in our country is Rs. $400 /-$ i.e. about 8 pounds per sample amounting to about 16 to 50 pounds per day. Hence it is not a cost effective means of monitoring neonates in the NICU. Non invasive monitoring is technologically simple and cost effective for monitoring the neonates. ${ }^{15}$

The present study was undertaken to monitor $\mathrm{ETCO}_{2}$ in ventilated neonates to assess the reliability of $\mathrm{ETCO}_{2}$ as a function of $\mathrm{PaCO}_{2}$ and also to correlate $\mathrm{ETCO}_{2}$ with $\mathrm{PaCO}_{2}$ in different clinical situations and various gestations. $\mathrm{ETCO}_{2}$ is the measurement of $\mathrm{CO}_{2}$ in the expired air and is assessed by mass spectrometry or infrared analyses. Capnometry measures the partial pressure of $\mathrm{CO}_{2}$ in the patients airway and is displayed as a numerical value in $\mathrm{mmHg}$ whereas capnography is the continuous graphic display of $\mathrm{CO}_{i}$ concentration versus time in a waveform with $\mathrm{CO}_{2}$ concentration on the $\mathrm{y}$-axis and time on the $x$-axis. The $\mathrm{CO}_{2}$ at the end of an exhalation i.e. end of a tidal breath represents alveoler $\mathrm{CO}_{2}$ and should in general be a good reflection of arterial $\mathrm{CO}_{2}{ }^{3}$

\section{MATERIALS AND METHODS}

The study was conducted during MarchAugust 1995, on all neonates ventilated during this period irrespective of the indication of ventilation, the gestation or the birth weight of the baby.

Each ventilated baby's $\mathrm{HR}, \mathrm{RR} \mathrm{SpO}_{2}$ and $\mathrm{ETCO}_{2}$ was continuously monitored. NIBP was measured every 60 minutes and arterial blood gases at least twice a day or more if the baby's condition demanded. Rest of the monitoring was done as per our NICU protocols for various clinical situations.

The sampling for arterial blood gas was done after a baby had been stabilized after putting on the ventilator and the arterial line had been inserted. At the time of drawing a blood gas sample, the value of End Tidal Carbon dioxide as shown by the LED display was noted. The ABG measurement was done on AVL $995 \mathrm{Hb}$ inhouse blood gas analyser and the printout was stored. The $\mathrm{ETCO}_{2}$ was continously monitored on Datex Cardiocap II. Table 1 shows the technical specifications of Datex Cardiocap II.

The methodology involves switiching on the monitor and allowing it to perform a 
self check, keeping the patient end of the sampling line open for it to draw room air and calibrate the flow. After the "flow calibration done", message appears on the screen the sampling line is connected to the patients' endotracheal tube adapter keeping the sampling tube positioned upwards. The sampling line was checked for any kink, collection of fluid or particulate matter in which case it was discarded. The patient's endotracheal tube position was confirmed radiologically or clinically by ensuring bilateral equal air entry and chest expansion and care was taken to rule out any displacement or blockage of tube. Pediatric endotracheal tube adapter, specially provided with the equipment was used with standard disposable Datex Sampling line to reduce the dead space to the greatest possible extent. Before each measurement the instrument was calibrated and only a stable LED display was treated as valid and noted down.

Table 1: The Technical Specifications of Dafex Cardio Cap II.

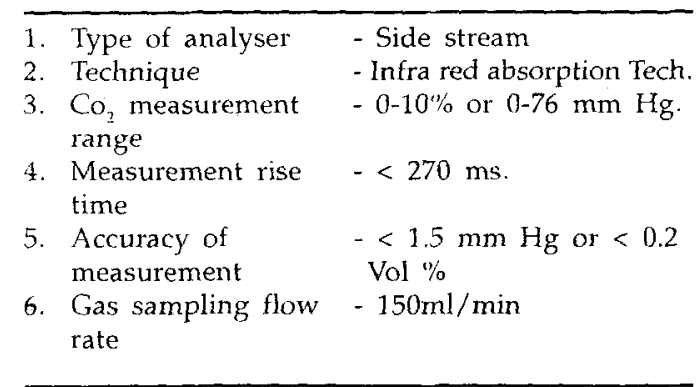

\section{RESULTS}

Simultaneous $\mathrm{PaCO}_{2}$ and $\mathrm{ETCO}_{2}$ values were recorded for neonates of 28-42 wks, 900-3400 gms, and who required ventilation for various indications like Meconium
Aspiration Syndrome (MAS), Severe Birth Asphyxia (SBA), Hyaline Membrane Disease (HMD) and recurrent apnoea. Babies were grouped into three groups based on their birth weights ( $<1500 \mathrm{gms}$, 1500-2500 gms and $>2500 \mathrm{gms}$ ), another three groups based on gestation in weeks [< $32 \mathrm{wks}, 32-36^{+6} \mathrm{wks}$ and $\left.37-41^{+6} \mathrm{wks}\right]$ and four groups based on their indication of ventilation (SBA, MAS, HMD and apnoea)

TABLe 2: $\mathrm{PaCO}_{2}$ and $\mathrm{ETCO}_{2}$ values along with correlation coefficient $(r)$ and $p$ value Gestation wise.

\begin{tabular}{lrrr}
\hline $\begin{array}{l}\text { Gestation } \\
\text { Wks }\end{array}$ & $\begin{array}{r}\text { Term } \\
37-41^{+6}\end{array}$ & $\begin{array}{r}\text { Preterm } \\
32-36^{+6}\end{array}$ & $\begin{array}{r}\text { Preterm } \\
<32\end{array}$ \\
\hline $\mathrm{n}$ & 80 & 60 & 12 \\
$\mathrm{PaCO}_{2}$ & $36.2 \pm 11.9$ & $35.2 \pm 11.2$ & $37.6 \pm 25.4$ \\
$\mathrm{ETCO}_{2}$ & $31.9 \pm 8.9$ & $28.9 \pm 7.8$ & $24.6 \pm 9.9$ \\
$\mathrm{r}$ & 0.81 & 0.61 & 0.73 \\
$\mathrm{p}$ & $<0.001$ & $<0.001$ & $<0.01$ \\
\hline
\end{tabular}

The data of simultaneously recorded end tidal carbon dioxide value and $\mathrm{PaCO}_{2}$ value was analysed statistically using correlation analysis and a correlation coefficient(r) was calculated using microstat. The correlation coefficient was then used along with the degree of freedom to compute the probability ( $p$ value) by using the correlation coefficient table. The $\mathrm{PaCO}_{2}$ and the $\mathrm{ETCO}_{2}$ values along with the correlation coefficient( $r$ ) and $p$ value are shown in Tables 2, 3 and 4 .

Table 2 reveals that the correlation coefficient was high and the $p$ value was statistically highly significant for term and preterms babies between $32-36^{+6}$ wks of gestation. The $p$ value was also significant for babies < 32 wks gestation but the significance was low. 
TABLE 3: $\mathrm{PaCO}_{2}$ and $\mathrm{ETCO}_{2}$ Values Along With Correlation Coefficient ( $r$ ) and $p$ value, Birth Weight Wise

\begin{tabular}{lrrr}
\hline Birth Wt & $>2.5 \mathrm{~kg}$ & $1.5-2.5 \mathrm{~kg}$ & $<1.5 \mathrm{~kg}$ \\
\hline $\mathrm{n}$ & 78 & 56 & 18 \\
$\mathrm{PaCO}_{2}$ & $36.2 \pm 11.6$ & $33.7 \pm 9.6$ & $43.6 \pm 25.2$ \\
$\mathrm{ETCO}_{2}$ & $31.9 \pm 8.7$ & $29.3 \pm 7.9$ & $23.5 \pm 8.5$ \\
$\mathrm{r}$ & 0.81 & 0.92 & 0.62 \\
$\mathrm{P}$ & $<0.001$ & $<0.001$ & $<0.01$ \\
\hline
\end{tabular}

Table 3 depicts a high degree of correlation between $\mathrm{ETCO}_{2}$ and $\mathrm{PaCO}_{2}$ in babies weighing $>2.5 \mathrm{~kg}$ and those weighing between $1.5-2.5 \mathrm{~kg}$. The $\mathrm{p}$ value was statistically highly significant for the above weight categories whereas the correlation coefficient was low for babies weighing $<1.5 \mathrm{~kg}$ even though there was statistical significance.

TABLE 4: $\mathrm{PaCO}_{2}$ and $\mathrm{ETCO}_{2}$ Values Along With Correlation Coefficient $(r)$ and $p$ Value, Indication of Ventilation Wise.

\begin{tabular}{lrrrr}
\hline Condition & MAS & SBA & $\begin{array}{r}\text { Recurrent } \\
\text { Apnoea }\end{array}$ & HMD \\
\hline $\mathrm{n}$ & 34 & 61 & 24 & 33 \\
$\mathrm{PaCO} 2$ & $35.5 \pm$ & $36.5 \pm$ & $32.0 \pm$ & $37.9 \pm$ \\
& 9.8 & 12.2 & 9.5 & 18.7 \\
$\mathrm{ETCO} 2$ & $32.6 \pm$ & $31.7 \pm$ & $28.2 \pm$ & $26.2 \pm$ \\
& 8.4 & 8.9 & 8.3 & 8.2 \\
$\mathrm{r}$ & 0.94 & 0.76 & 0.96 & 0.55 \\
$\mathrm{p}$ & $<0.001$ & $<0.001$ & $<0.001$ & $<.01-$ \\
& & & & .001 \\
& & & &
\end{tabular}

Table 4 reveals that the correlation coefficient was high and the $p$ value was statistically highly significant for babies with Severe Birth Asphyxia, Meconium Aspiration Syndrome and for Recurrent apnoea. The correlation coefficient was the lowest for babies with HMD, being 0.55.

\section{DISCUSSION}

The capnograph can be regarded as the most useful monitor in intensive care and is an excellent early warning system. Capnography has wide application in a variety of circumstances and its full clinical value and potential are lately being recognised. ${ }^{6}$

Treating respiratory problems is a critical part of neonatal intensive care. Continuous monitoring of both oxygen as well as carbon dioxide is important because the condition of the neonate can change suddenly. It is vital to ensure sufficient delivery of oxygen and equally important to ensure adequate carbon dioxide elimination from the body. ${ }^{5}$

Determining the partial pressure of carbondioxide $\left(\mathrm{PCO}_{2}\right)$ is crucial in critical care of neonate because $\mathrm{PCO}_{2}$ has a major influence on cerebral, pulmonary and peripheral circulation. Non-invasive $\mathrm{PCO}_{2}$ monitoring is useful to follow trends when unexpected changes in baseline $\mathrm{PCO}_{2}$ may occur. Such clinical situations include rapid weaning in RDS, hyperventilation for PPHN, decompensation in established BPD, transition to high frequency ventilation and possibly in infants at high risk of penumothorax. ${ }^{15}$

The continuous nature of non-invasive monitoring has made evident, the inaccuracies of samples obtained by skin puncture. Continuous non-invasive monitoring can be done with little risk to the patient and also helps in minimal handling of the sick neonate. ${ }^{8}$

Luft, in 1943 developed the principle of capnography from the knowledge that $\mathrm{CO}_{2}$ is one of the gases that absorbs Infrared radiation of a particular wavelength. 
Collier, in 1955 established the accuracy of Rapid Infrared $\mathrm{CO}_{2}$ analysis in determining alveolar $\mathrm{CO}_{2}$ and Ramwell in 1959 was the one to establish the value of end tidal sample but it was only in 1981 that Smalhout and Kalenda from Netherlands introduced capnography in routine clinical practice. $^{3}$

Carbon dioxide is produced by all the cells of all the tissues in our body as a by product of metabolism and is then transported via the venous circulation to the right side of the heart. The heart pumps it out into the pulmonary circulation where it perfuses the alveoli and gaseous exchange occurs. The $\mathrm{CO}_{2}$ is continously exhaled out as means to get the body rid of $\mathrm{CO}_{2}$ and also to maintain the gradient of $\mathrm{CO}_{2}$ between the blood and the alveolus. Thus $\mathrm{ETCO}_{2}$ not only monitors the ventilation but also serves to monitor the circulation and metabolism in a given subject. ${ }^{4}$

Normally the $\mathrm{ETCO}_{2}$ value closely follows the $\mathrm{PaCO}_{2}$ value but the two are not identical. $\mathrm{ETCO}_{2}$ value is $3-4 \mathrm{~mm} \mathrm{Hg}$ lower than the arterial $\mathrm{CO}_{2}$ value and this can be taken as a quantitative index of alveolar dead space.

A fall in $\mathrm{ETCO}_{2}$ value in a well ventilated stable neonate can be either a step wise fall or a gradual one. A step wise fall may indicate migration of ET tube into one main bronchus or sudden partial obstruction of the airway whereas a gradual fall can be due to increased minute ventilation either due to increased respiratory rate or increased peak inspiratory pressure. The fall can also be due to a falling cardiac output or due to decreasing pulmonary perfusion due to above causes or local pulmonary causes leading to dead space ventilation.6.8,9
In a well ventilated stable baby with a steady $\mathrm{ETCO}_{2}$ value there can be a sudden rise in $\mathrm{ETCO}_{2}$ value associated with infusion of bicarbonate or on the other hand, a gradual rise may indicate an increased metabolic rate eg. in fever or it may also herald onset of hypoventilation. In case of oesophageal intubation, the capnographic trace will be horizontal and capnometry will not detect any carbon dioxide ${ }^{8,10,11}$

In the present study, the correlation coefficient (r) ranged from 0.55 to 0.96 being the lowest in babies with HMD. The ETCO, correlated well with $\mathrm{PaCO}_{2}$ in term babies and preterms between 32 to $36^{+6} \mathrm{wks}$, in babies weighing $>2.5 \mathrm{~kg}$ and between 1.5 $2.5 \mathrm{~kg}$ and in babies with SBA, MAS and recurrent apnoea. The $p$ value in all these situations was $<.001$ being highly significant.

In preterms $<32 \mathrm{wks}$ and in babies weighing $<1.5 \mathrm{~kg}$, the $p$ value was $<0.01$ though there was statistical significance but the magnitude was low as the smaller babies have lower tidal volumes, smaller lung volumes and disproportionately high anatomic dead space. ${ }^{12}$

Babies with HMD had the lowest correlation coefficient $(0.55)$ because these babies have wide spread atelectasis, with consequent right to left shunting, pulmonary oedema and thus poor compliance leading to short time constants. A combination of these factors leads to dead space ventilation and a low or slowly rising $\mathrm{ETCO}_{2}$ in the face of a high or rapidly increasing $\mathrm{PaCO}_{2}{ }^{2}$

Geven et al analysed 12 babies: 9 preterms between 28-33 wks with severe RDS, 2 term babies with SBA and 1 term baby with MAS and revealed that there was 
a large variation in $\mathrm{PaCO}_{2}, \mathrm{ETCO}_{2}$ values and also that $\mathrm{ETCO}_{2}$ increased slowly with an increasing $\mathrm{PaCO}_{2}$. Their findings can be attributed to a very small sample size which predominantly consisted of preterms between 28-33 wks with severe RDS (75\% of the babies), thus catering to the smallest of the babies with Parenchymal Lung disease having short time constants.

We found that end tidal carbon dioxide correlates closely with $\mathrm{PaCO}_{2}$ in most clinical situations in neonates and the correlation was high in severe birth asphyxia, meconium aspiration syndrome and apnoea but was lowest in hyaline membrane disease. The correlation gestation wise was highest in term infants followed by those in the 32-36 wks gestation group and least in babies with gestation less than 32 weeks i.e. an inverse relationship was found with gestation. End tidal carbon dioxide is a good modality for monitoring arterial carbondioxide levels in babies non invasively and should be used in all level III NICUs in ventilated babies.

\section{REFERENCES}

1. Cloherty JP, Snyder EY. Blood Gas monitoring. Mantal neonatal care 1992: 3rd edn: 209-215.

2. Jose IraZurta. Monitoring in Paediatric Intensive care. Ind Jour Paed. 1993; 60: 5565 .

3. Adams AP. Capnography and Pulse oximetry. Recent advances in Anaesthesia and Analgesia. Churchill Livingstone. No. 16, 1989; 55-175
4. Paloheimo M, Valli M, Ahjopalo H. A guide to $\mathrm{CO}$, monitoring. Datex instrumentation Corp., 1983.

5. M. Ramex Salem. Hypercapnia, hypocapnia and Hypoxaemia. Seminars in Anaesthesia, 1987; Vol. 6: 3 (Sept.): 202-215.

6. Swedlow David B. Capnometry and Capnography; The anaesthesia Disaster early warning system. Seminars in anesthesia, 1986; Vol. 5: 3 (Sept.): 194-206.

7. Geven WB, Nagler, E, Th. de Boo and W. Lemmens. Combined transcutaneous Oxygen, Carbon dioxide tensions and end expired $\mathrm{CO}_{2}$ levels in severely ill newborns Adv Exp Med Biol. 1987; 220; 115-120.

8. Ward SA. The capnogram: Scope and limitations. Seminars in Anaesthesia 1987; 3 : 216-228.

9. Rolf Lanber, Bruno Seeberget MD, Alex Martin Zbinden. Carbondioxide analysers: accuracy, alarm limits and effects of intefering Gases. Can I Anaesth, 1995; 42: 7: 643-656

10. Fleether R. Airway Dead space. ETCO and Christian bohr. Acta Anaesthesiol Scand. 1984; 28: 408-411.

11. Lillie PE, Roberts JG. $\mathrm{CO}_{2}$ monitoring Anaesthesia Intensive Care, 1988; 16: 41-44.

12. Haab P. Factors influencing magnitude of the $\mathrm{CO}_{2}$ partial pressures in the body. Intensive Care Med. 1981; 7: 250.

13. Pryds O, Andersen GE, Friis-Hansen B. Cerebral blood flow reactivity in spontaneously breathing, preterm infants shortly after birth. Acta Paediatr Scand 1990; 79, 391-396.

14. National Committee for Clinical Laboratory Standards. Procedures for the collection of diagnositc blood specimens by skin puncture. 3rd NCCLS publication, Pennsylvania: 1991.

15. Mastering Infra-red Capnography. Z. Kalenda. Kerckebosch. -III. Netherlands, $1989 ; 49-172$. 